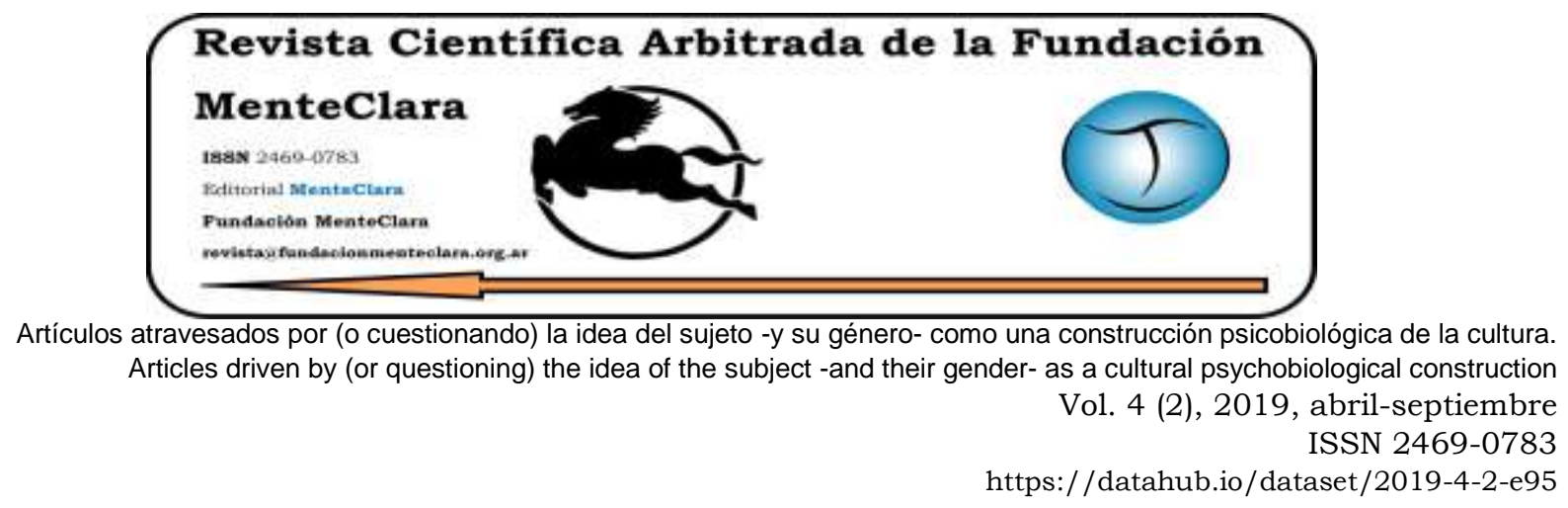

\title{
EN BUSCA DE UN POSIBLE TRATAMIENTO PSICOANALÍTICO DE LA LUDOPATÍA
}

\author{
IN SEARCH OF A POSSIBLE PSYCHOANALYTIC TREATMENT OF LUDOPATHY
}

Jesús Maria Dapena Botero jesusdapena50@hotmail.com

Universidad de Antioquía, Colombia.

Cómo citar este artículo / Citation: Dapena Botero, J. M. (2019). "En busca de un posible tratamiento psicoanalitico de la ludopatia". Revista Científica Arbitrada de la Fundación MenteClara, 4(2) abril-septiembre 2019, 111-131. DOI:

https://doi.org/10.32351/rca.v4.2.95

Copyright: (C) 2019 RCAFMC. Este artículo de acceso abierto es distribuido bajo los términos de la licencia Creative Commons Attribution 4.0 International License (CC BY 4.0). Recibido: 02/09/2019. Aceptado: 15/09/2019 Publicación online: 30/10/2019

Conflicto de intereses: Ninguno que declarar.

\section{Resumen}

Este artículo pretende, tanto desde las neurociencias como del psicoanálisis, evitar estigmatizar al adicto químico o comportamental de prejuicios morales, para considerarlo más bien un dependiente y no un degenerado, en la medida, que este tipo de dependencias son una enfermedad, son una patología dual y se trata de buscar un posible tratamiento psicoanalítico, en la singularidad del caso por caso.

\begin{abstract}
This article intends, both from the neurosciences and psychoanalysis, to avoid stigmatizing the chemical or behavioral addict from moral prejudices, to consider it rather a dependent and not a degenerate, to the extent that these types of dependencies are a disease; they are a dual pathology and it is about looking for a possible psychoanalytic treatment, in the uniqueness of the case by case.
\end{abstract}

Palabras Claves: Ludopatías; adicción; dependencia; tratamiento

Keywords: Gambling disorder; addiction; dependence; treatment 


\section{Introducción}

El concepto de adicción es bastante criticado por Nora Volkow, quien considera que, si bien, es posible que haya una cuestión genética, es más importante en las dependencias el desarrollo epigenético, el cual puede incrementarse por el consumo de las drogas, al producir comorbilidades con otros trastornos físicos y mentales e implicar muchas estructuras cerebrales, como una enfermedad crónica, con recaídas, desde el punto de vista neurocientífico, ya que ella defiende que las dependencias, no son degeneraciones morales, por lo que eran sometidos a tratamientos moralizantes a la manera de Pinel; puesto que, en realidad, las adicciones son una verdadera enfermedad; para ella, hay un cerebro adicto, en especial en relación con la cocaína y los opioides, de tal forma, que no es un problema, que se cure con fuerza de voluntad, por lo cual requieren de otros tipos de tratamiento (Volkow y Morales, 2015).

De todas maneras, esta psiquiatra mexicana considera que:

"Durante gran parte del siglo pasado, los científicos, que estudiaron las drogas y el consumo de drogas lo hicieron a la sombra de poderosos mitos y conceptos erróneos sobre la naturaleza de la adicción" (Volkow, 2018).

Pero, ella misma trabaja con neuroimágenes y se considera que es toda una autoridad en la comunidad científica, para estudiar este descontrol de sí mismo por la dependencia química y su acción sobre el córtex frontal, que se observa en alcohólicos, heroinómanos y consumidores de metanfetaminas, por un problema bioquímico con la dopamina en la corteza frontal (Baler y Volkow, 2006) (Wong et als., 2001).

De todas maneras, hace tiempos leí en un artículo suyo, en el que ella criticaba la palabra adicto, proveniente del latin, addictus, que, en Roma era un esclavo por deudas, dada su insolvencia, asunto que se legitimaba en el más antiguo Derecho Romano, hasta que alguien pudiera 
solventar la deuda y si no eran llevados más allá del río Tíber de la Roma imperial, como una suerte de ostracismo e incluso podía pasarse a la pena capital, por lo que ella decía que es mejor la palabra dependencia, que tiene que ver más con la realidad científica, para no esclavizarlos, ni condenarlos al espacio de la otredad, según la trabaja Rodolfo Moguillansky, sino que se han de considerar enfermos, que pueden llegar a tener un tratamiento, que pueda ser liberador de la adicción, puesto que, tampoco los dependientes padecen de ninguna labilidad, ni despliegan una actuación voluntaria ni hedonista, en sí mismas (Moguillansky, 2003) (ASEJER, 2017) (Jambrina y Bernal, 2017).

Respecto a la ludopatía, Nora Volkow piensa que es un reforzamiento, que el individuo humano o animal -perros, ratones y elefantes- buscan para sobrevivir y que hay personas, particularmente sensibles a dichos refuerzos, como si les hiciera falta un subidón de adrenalina ante la incertidumbre de que se ganará o no, en los juegos de azar, como leí en otro lugar, ya que ella no expone esto y esperar que se pueda erradicar la dependencia en todos los ámbitos, le parece un poco utópico (Jambrina y Bernal, 2017).

Pero, también, anota que, en los juegos de adivinanzas, en la Resonancia Magnética Funcional también hay una activación de la corteza prefrontal ventromedial y ventroestriatral e hipoactivación, lo cual tiene que ver con la severidad del trastorno y junto con Kalivas concluyen que la proyección glutamatérgica de la corteza prefrontal al núcleo accumbens o del placer es la vía final en las conductas ludopáticas; pero, la rehabilitación es posible (Kalvas y Volkow, 2005).

$\mathrm{Su}$ inicio es tan insidioso, como en cualquier dependencia, con un inicio suave, casi natural hasta que ganar se vuelve todo un gustazo enorme, ya que a todos nos gusta ganar; es como si un gusanillo se 
hubiera metido en nuestro cerebro, hasta convertirse en toda una enfermedad, de la que cuesta salir.

He aquí la corteza prefrontal ventromedial:

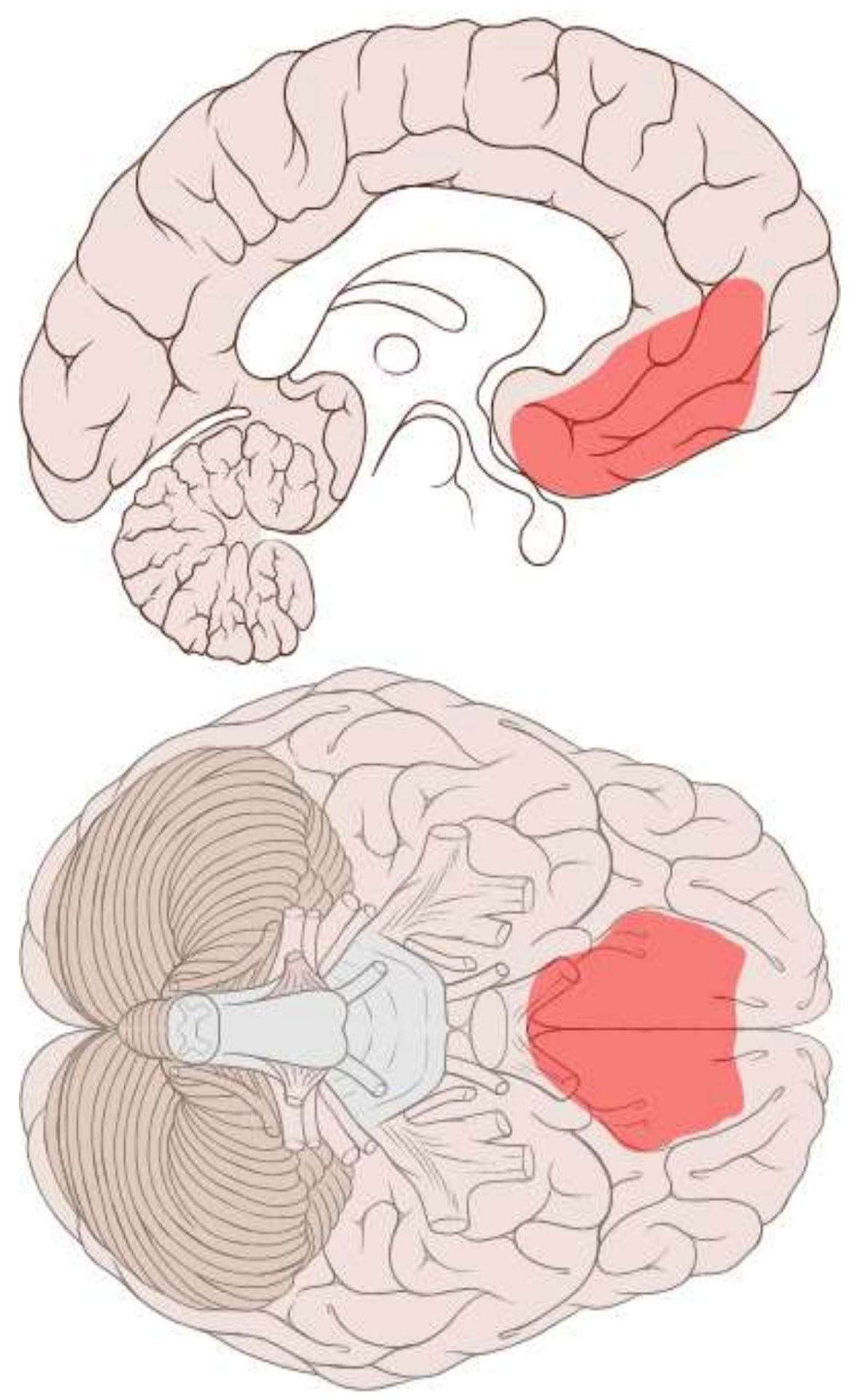

(C) Wikimedia 
Y aquí la ventroestratial:

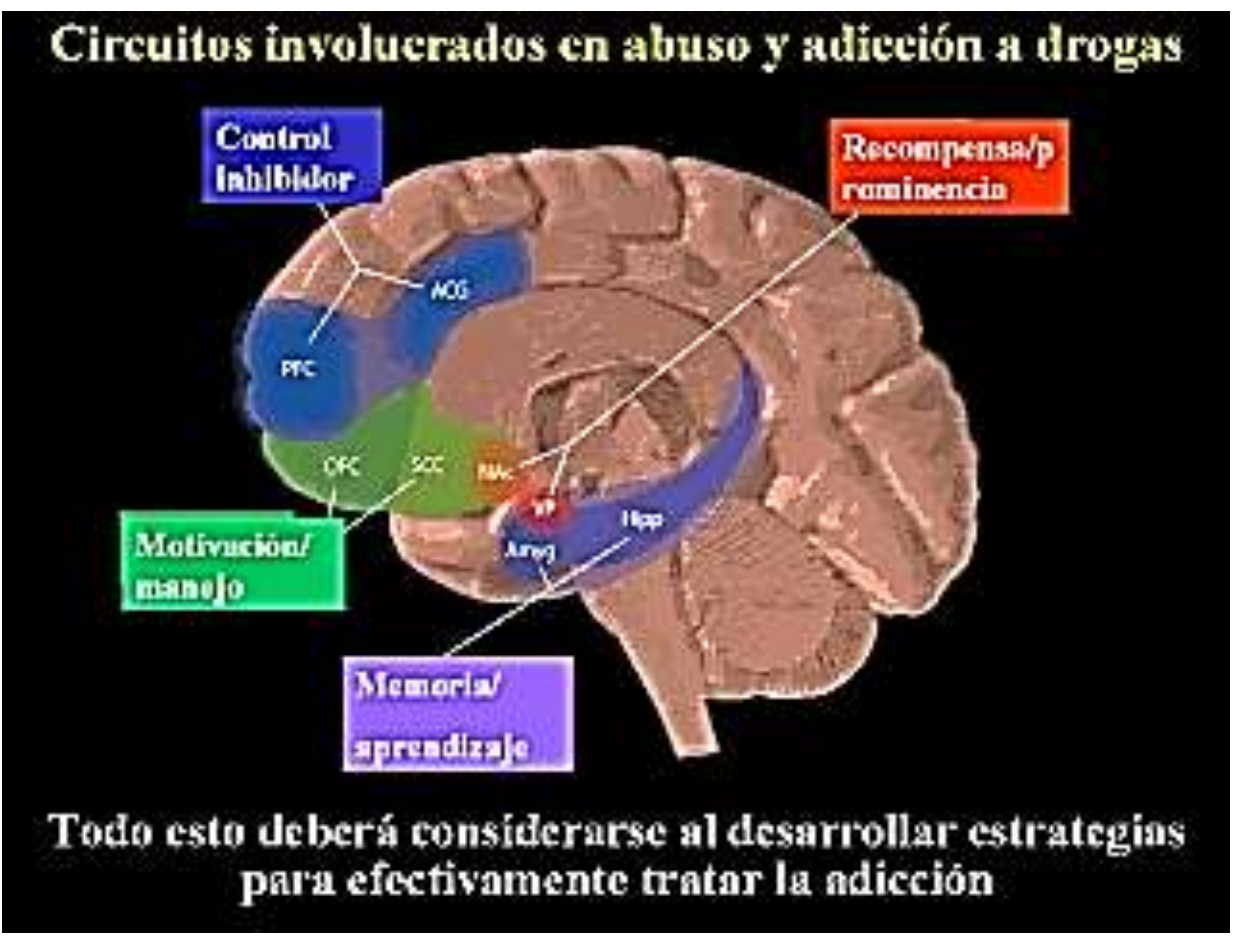

(C) National Institute on Drug Abuse

Y podemos acercarnos más al núcleo accumbens:

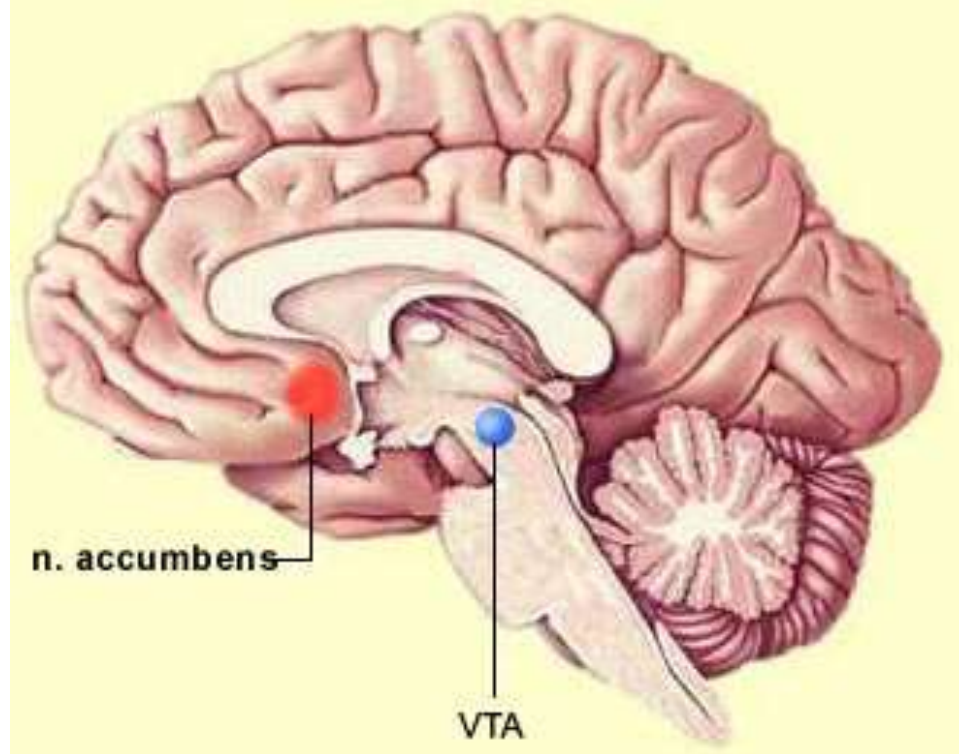

(C) Wikimedia

En donde, VTA es el área tegumental ventral, donde comienza la vía de la dopamina, que ayuda a producir recompensas y refuerzos, a partir de un estímulo determinado, que resulta positivo para el caso: 


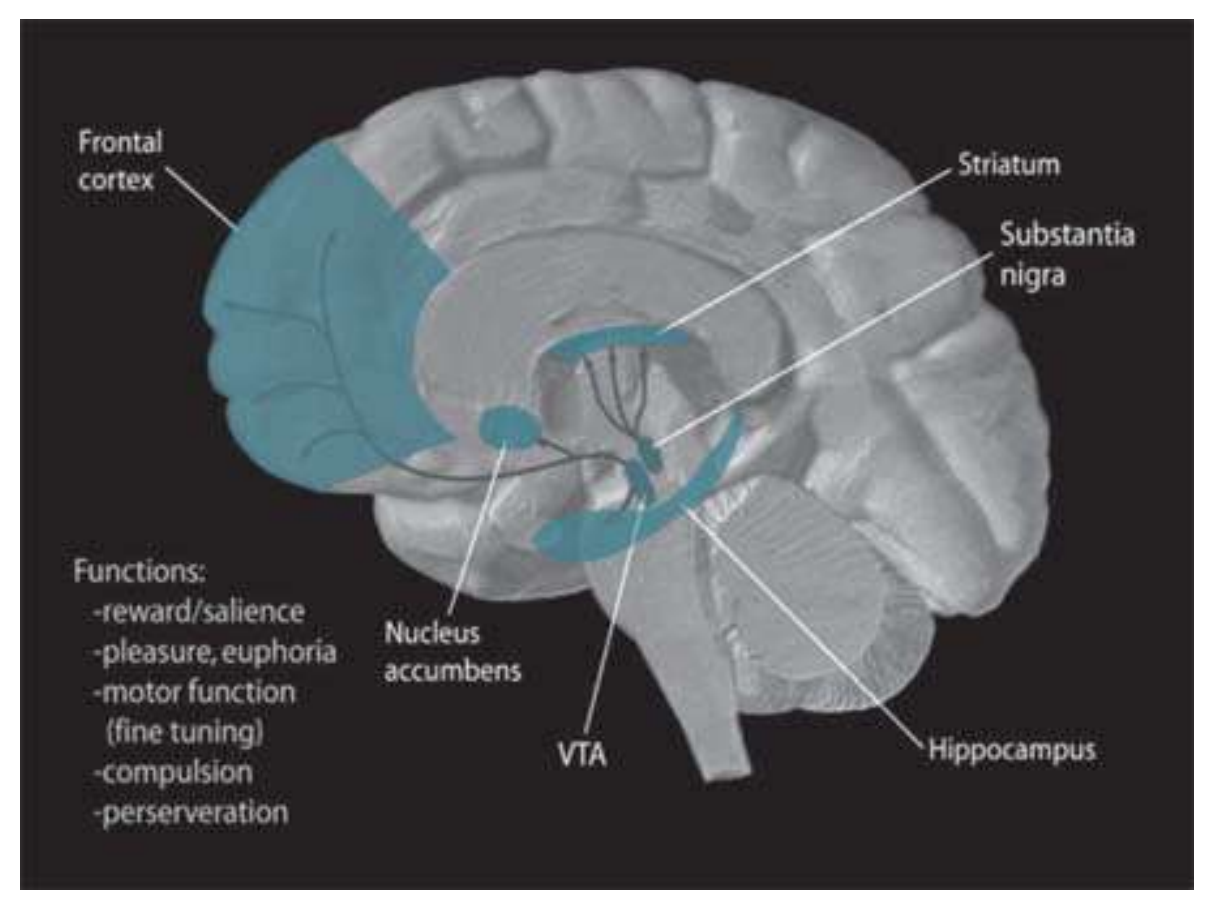

(C) Wikimedia

Y, ésta es la proyección glutamatérgica de la corteza prefrontal al núcleo accumbens, que puede llevar a una neurodegeneración comprobada en la resonancia magnética nuclear, en la medida que el glutamato produce apoptosis neuronal, o muerte neuronal, que es el neurotransmisor propio de esta vía, que va por esta proyección dada la excitotoxicidad, en la que el glutamato es una excitoxina natural de nuestro cerebro, que cuando es excesivo en las sinapsis mata neuronas, al producir apoptosis, al inundar de calcio las mitocondrias, con una detención del ciclo de Krebs dentro de ellas y el que hay producido puede empezar a hidrolizarse, en vez de ser generado (Manev et als., 1989). 


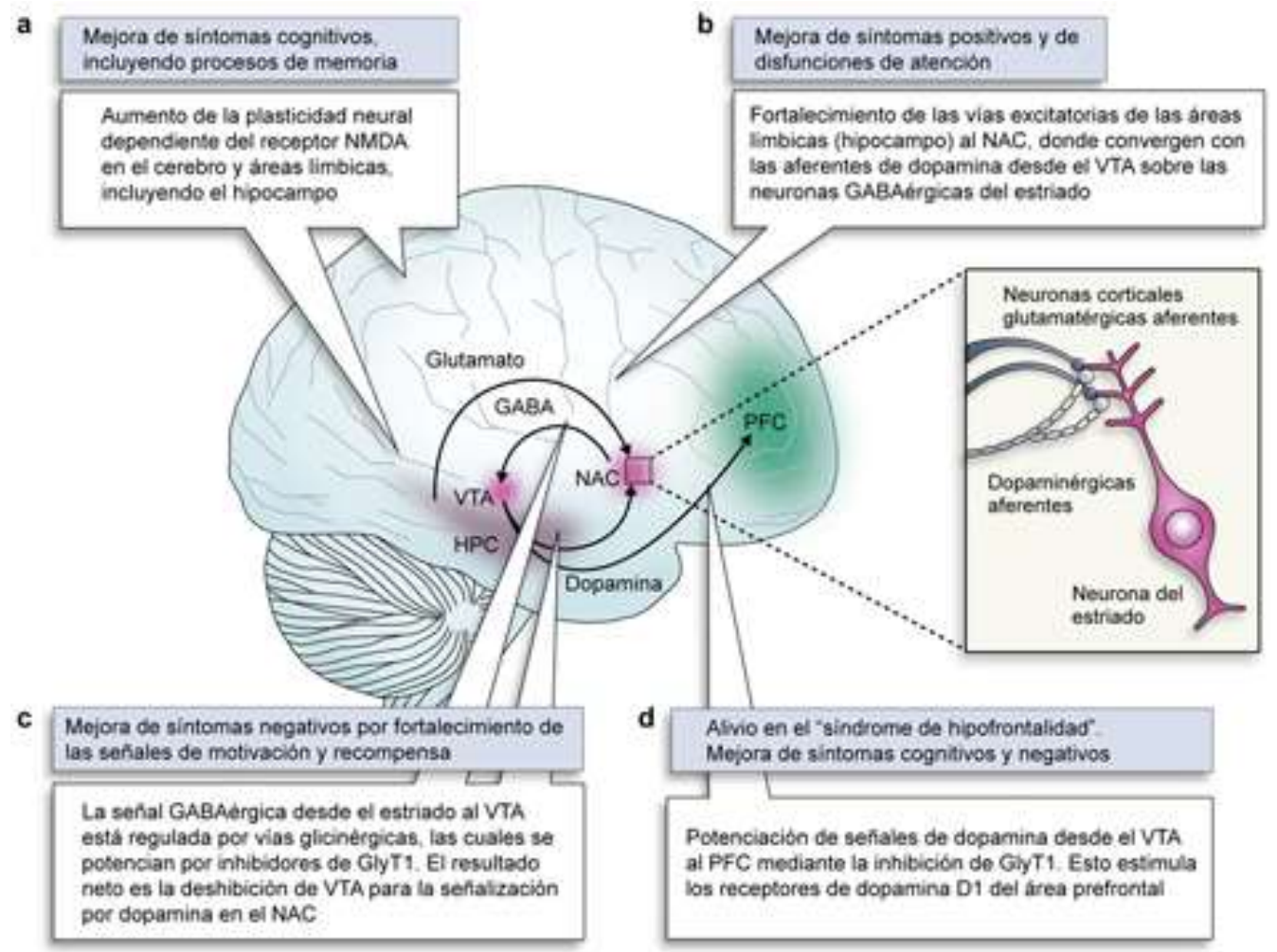

(C) 2018 Revista de Neurología (Giménez, Zafra y Aragó, 2018)

Hay que tomar, entonces, medidas preventivas, puesto que, en Europa, la industria del juego no conoce la crisis, con la liberalización gradual de dicho mercado, las máquinas tragaperras y las de Póker están cada vez, más presentes en bares y estancos, de una manera muy tecnificada; pues, con la ciencia de la estadística, el cálculo de probabilidades y un poco de humor, la gente joven descubre que los juegos benefician sobre todo a dueños y organizadores, hasta convertirse en un juego, que nunca ganas, y el ludópata con la ilusión de recuperar la fortuna perdida, sigue empecinados en ganar, de tal modo que el problema se acrecienta, cada vez con más oferta, incluso anunciadas en la televisión española; entonces, se ha encontrado que gente con problemas económicos acuden a las maquinitas para tratar de mejorar su situación, cuando la cosa va más de mal en peor (Centro de Ayuda Terapéutica, 2019). 
Pero, aunque vemos que en la mayor parte de los estudios citados de Nora Volkow se sigue hablando de adicción, a pesar de su crítica a esa palabra por su etimología, que remitía a esclavitud, ostracismo y muerte, encuentro que otros autores psicoanalíticos, lo consideran un intento de clasificación, para definir a un grupo de individuos, por su dependencia química o conductual, como práctica de goce, sin que se intente a atender a su subjetividad o sea que se clasifican por su modo de gozar, sin atender a la singularidad de cada sujeto, que tiene que ver con su historia, su estructura psíquica y el lugar, que ocupan en los espacios interpersonales y transculturales, que tiene para cada uno, el uso de algún químico o alguna conducta, como si todos fueran una serie de iguales, de donde desde un punto de vista meramente psiquiátrico, se prescriben los mismos fármacos, de acuerdo, con el tipo de adicción, para lograr la meta política de la abstinencia, según los criterios de la ciencia y sus métodos cuantitativos; pero, el psicoanálisis es un método cualitativo, que no piensa a las dependencias, como entidades patológicas autónomas, sino como un fenómeno que se da con los vínculos transculturales, en distintas estructuras psiquicas y distintas formas de reacción al consumo químico o conductual.

\section{Desarrollo}

La adicción, para el psicoanalista, es una abstracción del orden de lo Imaginario, del Imaginario Social, que tiene una naturaleza pulsional, que es indomesticable, de tal manera que el jugador compulsivo, no puede parar cuando quiera, pues se acuerda con Nora Volkow, que no es un vicio, con su connotación moralista, ni un acto voluntario ni hedonista, puesto que va más allá del principio del placer, sino que compulsa a la repetición por el influjo de la pulsión de muerte, como lo 
aclararía Freud en su obra "Más allá del principio del placen", de donde se vincula el goce con el mismísimo Tánatos (Freud, 1985) (Dapena, 2010).

Aunque, yo, como psicoanalista, no descartaría en su etiología, los elementos neurocientificos, que nos aporta, Nora Volkow, como lo hacen otros analistas, que dicen que el problema es sólo psíquico, para no mantener ese dualismo cartesiano de mente y cuerpo, ya superado por Franz Alexander (Alexander y Selesnick, 1966) y Donald Winnicott con su concepto de Psiquesoma (Winnicott, 1980); ya que pareciera que Nora Volkow puede explicar hasta la proyección glutamatérgica de la corteza prefrontal al núcleo accumbens y está más influenciada por la escuela conductista del condicionamiento operante (Tarpy, 2003) que sería una forma de aprendizaje, con base en el premio y el castigo, para estimular conductas adecuadas para la sociedad y desestimular las inadecuadas, como seria, en este caso, el juego patológico, donde el terapeuta es un Amo, que ejerce una ingeniería de la conducta, más allá de la libertad y la dignidad: (Skinner, 1998)

Al parecer la ludopatía es una dependencia, equivalente al alcoholismo o la drogodependencia, que se desencadena por una respuesta adrenérgica o glutamatérgica, que ocasiona un subidón, ante estímulos como el olor de la sala de juegos, cuando se da la reacción de ataque y fuga, por la vía mesolímbica, dopaminérgica, que activa la corteza, el núcleo accumbens, el sistema límbico, la amígdala, el hipocampo y el mesencéfalo, ocasionando un placer por el ataque y la incertidumbre de ganar o perder, que se va excitando cada vez más y con mayor frecuencia, base neurobiológica de la hiperexcitación y la biopsicología de la emoción de Cannon y Bard (Ganong, 1976), por respuesta ante un estrés agudo, que se repite y se repite. 
Aquí podemos ver la vía dopaminérgica, que se activa en tales momentos de excitación, ya sea con la dopamina, la noradrenalina, la adrenalina, o el glutamato:

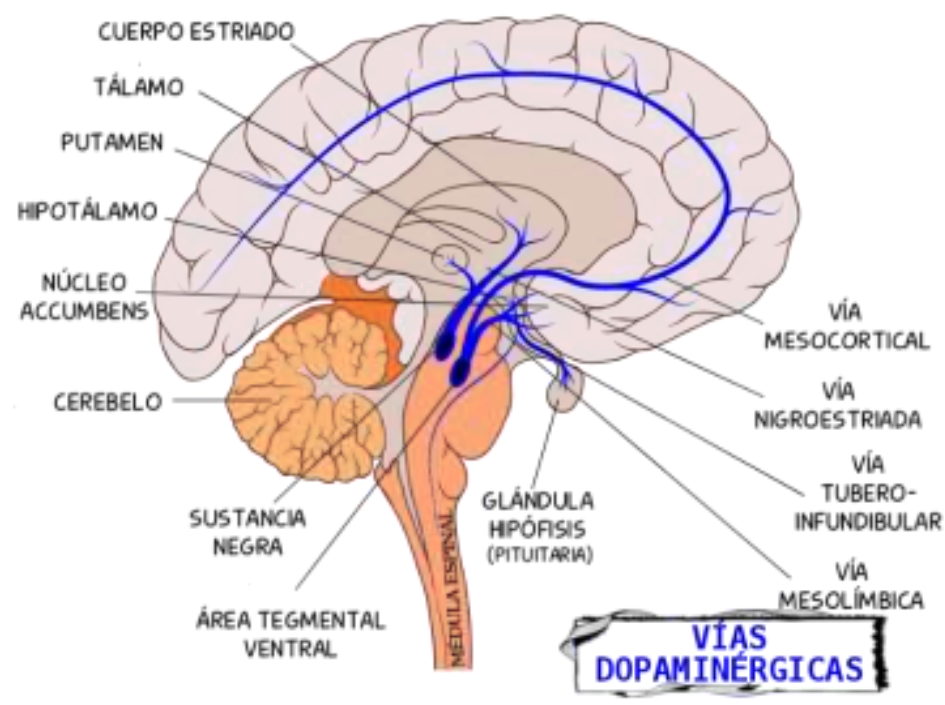

(C) Wikimedia

Lo cual lleva a la pérdida de dinero, la falta de confianza de los otros, amigos, familia, autoestima y saber el valor de las cosas como si el deseo estuviera embolatado y desorientado.

No es fácil, encontrar indicios de la ludopatía y la familia toma mucho tiempo en darse cuenta; pero, puede haber cambios notorios en el estado de ánimo del jugador, que puede pasar por una gama que va de la depresión a la exaltación y la irritabilidad.

El sujeto suele extender su horario laboral o estudiantil, con el móvil apagado para que no le entren llamadas, cae en contradicciones y acude a la mendacidad y la mentira, se atrasa en pagos, dice que le han robado dinero, o ha comprado cosas costosas o se dio unas vacaciones de raca mandaca.

El juego deviene compulsivo, cuando no se puede parar, por la necesidad de repetir y repetir y repetir esa descarga dopaminérgica, con 
lo que ese goce, coarta el deseo y aparece el desinterés por otro placeres, mientras se aísla y se va empobreciendo en todo sentido y no basta una decisión voluntarista, de voy a dejarlo, puesto que el goce inconsciente se impone al sujeto de la conciencia del que Descartes nos hablaba, porque aquello es, donde el yo de la consciencia no existe.

La compulsión no depende de la cantidad de dinero, que se gaste, en un contexto social que lo legaliza y hasta promueve a través de los medios masivos y puede hacerlo antes de los dieciséis, si se está bien desarrollado, como para aparentar dieciocho años, porque después todo está permitido en ese sentido, lo cual implica pensar la responsabilidad, que el Estado tiene en todo esto.

En estos sujetos es como si hubiera una fantasía de omnipotencia y de pensamiento mágico, con la certeza de que se puede ir contra las leyes del azar.

Por ello, nunca se debe aminorar el problema de parte de la familia, que estáen todo su derecho de expresar su decepción, su ira, su angustia; pero, nada se logra si se niega, se desmiente, si nos hacemos los ciegos, o los que tenemos los oídos sordos; hay que intentar generar cierta egodistonía respecto al sintoma, para evitar mantener el asunto como un saber, que no sabe y se debe inducir a una búsqueda de ayuda y tratar de cumplir con tratamiento, con compromiso; pero, esto no garantiza una auténtica demanda por parte del paciente, ni de una verdadera alianza terapéutica, que el paciente finge en un como si, se defiende con un semblante y muchas veces, nos trata a psiquiatras, psicólogos y psicoanalistas como si fuéramos unos burócratas de la salud, incluso sin aprender el nombre del supuesto terapeuta.

Desde luego, el terapeuta no debe hacerse el cómplice del síntoma del sujeto, sino que es algo dificil de curar; pero, que se trata de un camino 
largo, trabajoso y con recaídas, como se hace en cualquier Unidad de Dependencias.

Por ello, una de las cosas es necesario, que el paciente renuncie a la omnipotencia de ser superior a las leyes del azar, en la medida que lo azaroso mismo se contemple como una verdad ontológica, con ciertas leyes deterministas, en un contexto de sistemas complejos y sistemas abiertos, que matizan el determinismo, que permite cierta predictibilidad estadística, gracias al cálculo de probabilidades, que como los sueños, parafraseemos a Calderón de la Barca, probabilidades son y mantienen una ligazón con lo ilusorio de la vida, sin que se pongan los pies en la tierra, cosa que se percibe en los tests de figura humana-Machover-, la casa y el árbol, o las figuras del test de la familia, que no tienen una base terrenal, lo que da cuenta de cierto desfasaje con el principio de realidad.

Pero, cada caso debe ser pensado en la singularidad del caso por caso, con tácticas, estrategias y metas políticas, como nos enseñara Adalberto L.A. Perrotta (Perrotta, 1979)

La meta política no sería el abandono de la adicción, como ideal de salud; de tal forma, que, los psicoanalistas debemos poner en suspenso nuestros propios ideales, para mantener cierta economía libidinal y que no se dé el desencadenamiento de una psicosis, en busca de un cambio en la posición subjetiva del paciente, que le permita estar compensado.

Y podrian ser útiles, encuadres bipersonales y multipersonales, grupales y/o familiares, o combinación de dos o tres, modelos y, si es necesaria, una evaluación psiquiátrica para usar controladores del ánimo, que funcionan como de impulsos o antidepresivos, como el topiramato, la pregabalina o la lamotrigina o antiobsesivos como la fluvoxamina o cloimipramina, que controlan lo obseso compulsivo; pero, 
más como un coadyuvante, ya que lo más importante es la cura por la palabra.

Si el paciente no se compromete o deserta del tratamiento, puede ayudarse a la familia, muchas veces en conjuntos multifamiliares, con varias familias coordinadas por un terapeuta.

\section{Los grupos pueden ser bastante eficientes.}

Se habla menos de cura, ya que lo que suele darse es una estabilización, en las dependencias y en especial en caso de la dependencias conductuales como la ludopatía, que se considera estabilizada cuando se mantiene la abstinencia, con la recuperación del deseo, ya que no hay búsqueda insaciable de momentos de plenitud transitorios de vivencia de la satisfacción, de la Cosa, como la llama Lacan, esa cosa mortífera, a la par que se da un mayor interés por otras actividades y el lazo social, ya que, en la medida que se logre algún trabajo elaborativo, podría darse un deseo de reparación, en términos kleinianos, en un momento más creativo, con una perspectiva de mayor capacidad para tolerar las pérdidas, ya que muchas veces hay un duelo patológico e inconsciente (Lacan, 2003) (Klein y Riviere, 1982).

Para la recuperación y estabilización se precisa de una abstinencia sostenida y un trabajo psicoterapéutico de reflexión, que le permitan al sujeto la introspección, el insight, suficiente para que el sujeto alcance a comprender por qué se desencadenó tal sintoma, que lo ha llevado a meterse en un círculo infernal de pérdida tras pérdida; lo que puede llevarlo a encontrar nuevos sentidos, recordar, repetir en el vínculo terapéutico y elaborar; el terapeuta es fundamental como sostén, como madre suficientemente buena o con capacidad de rêverie, si se prefiere a Winnicott o a Bion. (Winnicott, 1998) (Bion, 2013) 
Ante una posible recaída, que suelen suceder, hay que mostrarle que es una repetición, que en el sintoma uno repite, de cosas como las que le suceden a uno cuando anda en la eterna repetición de lo mismo y de lo que se trata es seguir trabajando sobre ello, que otras cosas puede estar repitiendo, aunque el tratamiento sea largo, trabajoso y dificil, de tal manera, que es importante crear ansiedad respecto al sintoma, para que este pase de ser egosintónico a distónico, de tal manera que deje de ser un pasaje al acto impulsivo sino que medien, huellas mnémicas, entre la percepción y la motricidad como nos lo muestra Sigmund Freud (2011) en el esquema del peine y pase de ser una suerte de arco reflejo, para construir algo así, algo ya probado por las neurociencias, a través de neuroimágenes; ya que cuando hay un sujeto decidido la recuperación es posible:

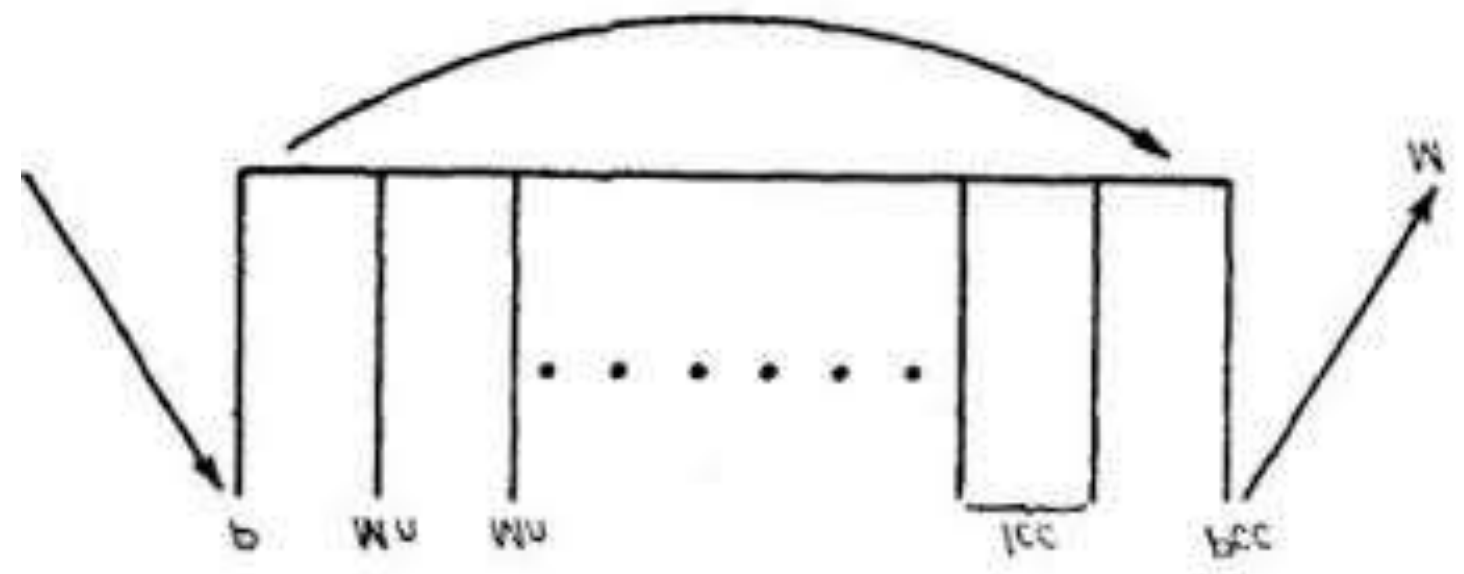

Pero, a nivel institucional, hay que ver qué se puede elegir como tratamiento en ese marco, de acuerdo con puntos de urgencia y hacer uso de una psicoterapia focalizada; el paciente suele quejarse, sin hacer una demanda explícita, lo cual es preciso, en el marco institucional, ya que la queja no es suficiente y esperar que la demanda surja, como lo comprobé yo, en el caso de un paciente (Dapena, 2014), al mostrarle su posición subjetiva ante la existencia, los síntomas, ver qué implicación tiene el paciente en lo que le pasa y si es posible que aparezca una 
pregunta, un enigma, sobre ese saber que no se sabe, ya que él mismo sabe más de lo que dice.

Es parte de nuestra ética plantearnos cuál será la meta política de nuestro trabajo, cómo trabajar el sufrimiento psíquico, que cosas se dejarán de lado y llevar a un pregunta por el deseo, que pueda el paciente recibir nuestras intervenciones y que hagan cadena significante en él, en la cura por la transferencia y hacer el sintoma analizable, para poner límites al goce, en la medida de que el sujeto se haga responsable de lo que le pasa, para que el sujeto tenga una disminución del sufrimiento, sin llegar a un cierre, así el paciente entre en una resistencia incoercible; pero, que sepa que lo que le pasa tiene relación con él mismo, para que después se dé una verdadera demanda de análisis; pero, el sujeto es quien elige, sin abocar al paciente a un callejón sin salida, que es lo que el psicoanálisis puede aportar en el espacio terapéutico. (Dapena, 2014) (Lencero, y Menéndez, 1996)

\section{Imaginario colectivo}

En la investigación de la ludopatía hay que tener en cuenta el imaginario colectivo, así sea en pequeñas muestras de una población específica o lo que el psicólogo social rumano Serge Moscovici en1981 se refería como representación social, en la medida que reformula el concepto de Émile Durkheim de representación colectiva ( Durkheim, 1898), que para el sociólogo francés eran diferentes a las construidas en el mundo de lo social; pero, para el rumano, son construcciones simbólicas, que se dan en la interacción social, de donde son dinámicas y no determinan las individuales, al ser formas especificas de entender y comunicar la realidad y se transmiten mediante interacciones sociales, de donde son mecanismos explicativos, referidos a una clase general de 
ideas y creencias, por transmisión interindividual, en la vida cotidiana, que crean mitos, mitologias y sistemas de creencias tradicionales, como parte del sentido común, que como se dice es el menos común de los sentidos, con el fin de dar sentido a la sociedad, de tal forma que lo desconocido se torne familiar (Álvaro, 2009), lo que nos lleva a la estigmatización y la condena al espacio de la otredad, al que son sometidos las personas con dependencias químicas o conductuales, que deben pasar de ser consideradas un vicio y una debilidad, en vez de ser vistos como enfermos, algo que aún se mantiene en el imaginario colectivo. Recuerdo un hostelero, donde iba a almorzar cuando trabajaba en Servicio de Prevención Asistencial de Drogodependencias de Vilagarcía de Arousa, quien, de una manera bastante obstinada, me decía que no eran más que unos viciosos, que debería dejar el Estado, que muriesen en el abandono, y no gastar nuestros impuestos en ellos.

\section{Escalas de Likert}

Para investigar la situación de las ludopatías y otras adicciones químicas, es útil usar escalas de Likert, las cuales son instrumentos psicométricos, en las que el encuestado debe responder afirmativa o negativamente a una afirmación, que se hace dentro de ellas, en una escala ordenada y unidimensional, que además de investigar a un sujeto singular, también es muy utilizada en las ciencias sociales.

Tal instrumento fue ingeniado por el psicólogo organizacional estadounidense, Rensis Likert para medir actitudes.

Pero, volviendo a nuestro problema investigativo; se trataria de que se tenga clara la concepción de la muestra sobre estas modalidades psicopatológicas y su posible tratamiento. 
Y, en una investigación realizada con alumnos del quinto año de psicología de la universidad de La Plata se encontró que los alumnos no rechazan la posibilidad de ayudar al ludópata, ya que el jugador compulsivo es considerado como el portador de una enfermedad, lo cual avala la posibilidad de un tratamiento y una recuperación. (De Souza y Marcheschi, 2015)

Como las escuelas, que suelen tratar el problema son la cognitivoconductual y el psicoanálisis, haré caso omiso de la primera, ya que lo que me interesa es un posible tratamiento psicoanalítico, así contemple el ideario neurocientífico de la doctora Nora Volkow con sus neuroimágenes funcionales, ya que no parecen ser tan dispares las neurociencias y el psicoanálisis, tal como lo plantearon, Ansermet y Magistretti, psicoanalistas más neurocientíficos ginebrinos. (Ansermet y Magistretti, 2006) (Ansermet y Magistretti, 2012)

Bergler, un psiquiatra y psicoanalista vienés, que se radicara en los Estados Unidos, por causa antisemitismo hitleriano, fue el primero en reportar el éxito del tratamiento psicoanalitico mediante psicoterapia psicoanalítica desde la psicología del yo, en 1957, que Freud había tratado en un trabajo de psicoanálisis aplicado, en "Dostoievsky y el parricidio ", sin ninguna aplicación clínica, como un intento de solucionar conflictos con las imagos parentales, el deseo inconsciente de perder, como necesidad de castigo por las pulsiones agresivas, experimentadas hacia el padre, que sería lo que Bergler comprobaría en la clínica, ya que la subjetividad del jugador patológico está constreñida por esa conducta compulsiva, con una carga de culpa inconsciente, que busca el castigo. (Bergler, 1957) (Freud, 1985) 


\section{Conclusión}

En mi pregunta sobre un posible tratamiento psicoanalitico del sujeto ludópata, encontré tanto desde el punto de vista psicoanalítico, como las neurociencias, que se debe considerar una enfermedad o un sintoma de una estructura psicopatológica, que es hacia la que debe orientarse un tratamiento, que ha de ser comprendido desde su patofisiologia, desde la psicopatología y el entendimiento del entorno sociofamiliar, que rodea al paciente, en el que yo considero que el mejor tratamiento posible es una psicoterapia focalizada, prolongada en el tiempo. La meta política debe ser tratar de estabilizar al paciente y evitar su estigmatización y permitir la toma de conciencia de que es un padecimiento, que hace sufrir a uno mismo y los otros, que devenga egodistónico y se mantenga una muy buena alianza terapéutica. 


\section{Referencias}

Alexander, F y S.T Selesnick (1966) The history of psychiatry: an evaluation of psychiatric thought and practice from prehistoric times to the present. Harper $\&$ Row, New York, $490 \mathrm{pp}$.

Álvaro, J. L. (2009) Representaciones sociales en Román Reyes (Dir): Diccionario Crítico de Ciencias Sociales. Terminología Científico-Social, Tomo 1/2/3/4, Ed. Plaza y Valdés, Madrid http://webs.ucm.es/info/eurotheo/diccionario/R/representaciones_sociales.htm

Ansermet, F. y P. Magistretti. (2006) A cada cual su cerebro. Editorial Katz, Buenos Aires, $237 \mathrm{pp}$.

Ansermet, F. y P. Magistretti. (2012) Los enigmas del placer. Editorial Katz, Buenos Aires, $213 \mathrm{pp}$.

ASEJER. (2017) La adicción no es un vicio. http://www.asejer.es/?p=4912

Baler, R. y N. Volkow. (2006) Drug addiction: the neurobiology of disrupted self control, Trends in molecular medicine, 12(12), pp. 559-566.

Bergler, E. (1957) The psychology of gambling. Hill and Wang, New York, 244 pp.

Bion, W. R. (2013) Volviendo a pensar. 6ª edición, Hormé-Paidós, Barcelona, 225 pp.

Centro de Ayuda Terapéutica (2019) Reflexiones terapéuticas. http://www.ludopatiazaragoza.com/category/sin-categoria/

Dapena, J. (2010) Goce y pulsión de muerte. https://www.academia.edu/28705380/GOCE_Y_PULSIÓN_DE_MUERTE_por_JESÚS_M ARÍA_DAPENA_BOTERO_1._DE

Dapena, J. (2014) Buen futuro, Guillermo. https://www.academia.edu/13125572/BUEN_FUTURO_GUILLERMO

De Souza, S. y L. Marcheschi. (2015) Ludopatía, un tratamiento posible. VII Congreso Internacional de Investigación y Práctica Profesional en Psicología XXII Jornadas de Investigación XI Encuentro de Investigadores en Psicología del MERCOSUR. Facultad de Psicología - Universidad de Buenos Aires, Buenos Aires.

Durkheim, E. (1898) Représentations individuelles et représentations collectives. Revue de Métaphisique et de Morales VI: 273-300. 
Freud, S. (2011) La interpretación de los sueños en (2 tomos). Alianza Editorial, Madrid, $912 \mathrm{pp}$.

Freud, S. (1985) Más allá del principio del placer en Obras completas (t. XVIII) Amorrortu editores, Buenos Aires, 1985, pp. 1- 63.

Freud, S. (1985) Dostoievski y el parricidio en Obras completas (t.XXI). Amorrortu editores, Buenos Aires, pp. 171-192.

Ganong, W. F (1976). Manual de fisiología médica. 5ª edición, Manual Moderno, México, $671 \mathrm{pp}$.

Giménez C, Zafra F, Aragón C. Fisiopatología de los transportadores de glutamato y de glicina: nuevas dianas terapéuticas. Revista Neurológica 2018; 67 (12):491-504 doi: https://doi.org/10.33588/rn.6712.2018067

Jambrina, J. y J. Bernal. (2017) Nora Volkow: "En Estados Unidos estamos padeciendo la mayor epidemia de opiáces de la historia". https://www.jotdown.es/2017/06/noravolkow-estados-unidos-estamos-padeciendo-la-mayor-epidemia-opiaceos-la-historia/

Kalvas, P. W. y N. Volkow. (2005) The neural basis of addiction: a pathology of motivation. American Journal of Psychiatry 162(8): 1403-1413.

Klein, M. y J. Riviere (1982). Amor, odio y reparación. Paidós Ibérica, Barcelona, 124 pp.

Lacan, J. (2003) Seminario 8: La transferencia. Paidós Ibérica, Barcelona, 448 pp.

Lencero, F. y A. Menéndez. (1996) Sobre un caso de terapia psicoanalítica en una institución pública. Revista de la Asociación Española de Neuropsiquiatría, 16 (58): 279284.

Manev, H. et als. (1989) Delayed increase of Ca2+ influx elicited by glutamate: role in neuronal death. Molecular Pharmacology 36(1):106-12.

Moguillansky, R. (2003) Pensamiento único y diálogo cotidiano. Buenos Aires: Libros del Zorzal, Buenos Aires, p. 17.

Perrotta, A.L. (1979) Seminario Planificación en Psicoterapia. ICONTEX, Medellín

Skinner, B. F. (1998) Más allá de la dignidad y la libertad. Martínez Roca, Barcelona, 208 pp. 
Tarpy, R. M. (2003) Aprendizaje: teoría e investigación contemporáneas. McGrow Hill, Madrid.

Volkow, N. (2018) De qué manera la ciencia ha revolucionado el conocimiento de la adicción a drogas. National Institute on Drug Abuse. https:// www.drugabuse.gov/es/publicaciones/las-drogas-el-cerebro-y-elcomportamiento-la-ciencia-de-la-adiccion/prefacio

Volkow, N. D. y Morales, M. (2015) The brain on drugs: From reward to addiction. Cell, 162, 712-725. 2015.

Winnicott, D. (1980) La familia y el desarrollo del individuo. Hormé, Buenos Aires, p.33.

Winnicott, D. (1998) Los bebés y sus madres. Paidós, Barcelona, 162 pp.

Wong, G-J y cols. (2001) Brain dopamine and obesity. The Lancet, 354-35. 